\section{Case Reports in Ophthalmology}

Case Rep Ophthalmol 2013;4:129-133

DOI: 10.1159/000355385

Published online: September 21, 2013
This is an Open Access article licensed under the terms of the Creative Commons Attribution-NonCommercial 3.0 Unported license (CC BY-NC) (www.karger.com/OAlicense), applicable to the online version of the article only. Distribution permitted for noncommercial purposes only.

\title{
Pattern Dystrophy of the Macula in a Case of Steinert Disease
}

\author{
Filipe Esteves ${ }^{a, b}$ Rosa Dolz-Marco ${ }^{b}$ Pablo Hernández-Martínez ${ }^{b}$ \\ Manuel Díaz-Llopis ${ }^{\text {b, }}$ Roberto Gallego-Pinazo ${ }^{\text {b }}$ \\ ${ }^{a}$ Department of Ophthalmology, Centro Hospitalar de Entre o Douro e Vouga, \\ Santa Maria da Feira, Portugal; ' ${ }^{\text {Unit }}$ of Macula and Medical Retina, Department of \\ Ophthalmology, University and Polytechnic Hospital La Fe, and ${ }^{\mathrm{C}}$ Faculty of Medicine, \\ University of Valencia, Valencia, Spain
}

\section{Key Words}

Maculopathy · Pattern dystrophy · Acquired vitelliform deposit · Myotonic dystrophy . Steinert disease

\begin{abstract}
Introduction: Myotonic dystrophies are typically associated with ocular complications like ptosis, weakness of the ocular muscle and cataracts, but also with less recognized retinal changes. Case Report: A 41-year-old female with type 1 myotonic dystrophy complained of progressive vision loss. Slit lamp examination revealed the presence of typical bilateral polychromatic cataract with posterior subcapsular component. Dilated fundus examination was remarkable for bilateral macular depigmented changes. Multimodal imaging analysis of the macula suggested the presence of a butterfly-shaped pattern dystrophy. Discussion: In cases of myotonic dystrophies it is of great relevance to analyze the presence of retinal changes that might limit the visual improvement following cataract extraction.
\end{abstract}

(C) 2013 S. Karger AG, Basel

\section{Introduction}

Pattern dystrophies of the retinal pigment epithelium (RPE) represent a group of heterogeneous disorders characterized by the development of a variety of patterns of yelloworange-grayish pigment deposition above the RPE within the macular area [1]. These have traditionally been subdivided into 4 major patterns: butterfly dystrophy, reticular dystrophy, fundus pulverulentus and adult-onset foveomacular vitelliform dystrophy. The phenotype may vary among affected family members and even between the 2 eyes of the

Roberto Gallego-Pinazo, MD, PhD

Department of Ophthalmology

University and Polytechnic Hospital La Fe

Bulevar Sur s/n., ES-46026 Valencia (Spain)

E-Mail robertogallegopinazo@gmail.com 
Esteves et al.: Pattern Dystrophy of the Macula in a Case of Steinert Disease

same patient [2]. The age of onset is highly variable, although most patients tend to remain asymptomatic until the fourth or fifth decade. The course is usually benign, but the disease may progress, leading to geographic atrophy of the RPE and/or choroidal neovascularization, therefore resulting in severe vision loss.

Pattern dystrophies have been occasionally associated with a variety of systemic disorders. Among these, myotonic dystrophy is an inherited disorder accompanied by progressive wasting and weakness of the distal muscles and myotonia. It is typically associated with ocular complications including ptosis, weakness of the ocular muscle and cataracts [3-5]. Herein, we report a clinical case illustrating the association of a pattern dystrophy of the RPE with type 1 myotonic dystrophy.

\section{Case Report}

A 41-year-old Hispanic female diagnosed with type 1 myotonic dystrophy (Steinert disease) was referred for ophthalmologic examination with the chief complaint of progressive vision loss. Her best-corrected visual acuity was 20/32 in her right eye and 20/40 in her left eye. Ocular motility was normal. She had bilateral ptosis with abnormal elevator function. Slit lamp examination revealed the presence a bilateral polychromatic cataract with posterior subcapsular component.

Dilated fundus examination was remarkable for macular pigmentary changes with multifocal yellowish depigmented patches within the macular area in both eyes (fig. 1). Fundus autofluorescence highlighted a branching linear pattern of mixed hyper- and hypoautofluorescence limited to the macular area in both eyes (fig. 1).

Optical coherence tomography images showed diffuse subretinal hyperreflective material between the photoreceptor layer and the RPE in both eyes. Larger focal vitelliform lesions were also evidenced. No subretinal or intraretinal fluid was found in association with the deposits (fig. 2).

\section{Discussion}

Type 1 myotonic dystrophy (Steinert disease) is a chronic, slowly progressing, highly variable, multisystemic disease produced by the expansion of the cytosine-thymine-guanine (CTG) triplet repeat in the DMPK gene (chromosome 19), which codes for myotonic dystrophy protein kinase [6, 7]. It is clinically characterized by muscular dystrophy, heart conduction defects, endocrine changes and myotonia. Although several reports previously described the ocular involvement in myotonic dystrophies, the majority of them refer to palpebral ptosis, cataract or ocular motility changes [3-5]. Very few publications raise the concern of retinal involvement in these patients with anecdotal reports about lamellar macular holes and foveoschisis [8], pigmentary changes of the RPE [9-12] or uveal melanoma [13].

In conclusion, although myotonic dystrophies are typically associated with cataracts, ophthalmologists should be aware of the presence of retinal changes that might limit the visual improvement following cataract extraction. 
Esteves et al.: Pattern Dystrophy of the Macula in a Case of Steinert Disease

\section{Disclosure Statement}

The authors have no conflicts of interest to disclose.

\section{References}

1 Marmor MF, Byers B: Pattern dystrophy of the retinal pigment epithelium. Am J Ophthalmol 1976;13:112116.

2 Yang Z, Li Y, Jiang L, Karan G, Moshfeghi D, O’Connor S, Li X, Yu Z, Lewis H, Zack D, Jacobson S, Zhang K: A novel RDS/Peripherin gene mutation associated with diverse macular phenotypes. Ophthalmic Genet 2004;25:133-145.

3 Pénisson-Besnier I, Lamirel C: Ocular disturbances in neuromuscular disorders. Rev Neurol (Paris) 2008;164:902-911.

4 Romeo V: Myotonic dystrophy type 1 or Steinert's disease. Adv Exp Med Biol 2012;724:239-257.

5 Turner C, Hilton-Jones D: The myotonic dystrophies: diagnosis and management. J Neurol Neurosurg Psychiatry 2010;81:358-367.

6 Mahadevan M, Tsilfidis C, Sabourin L, Shutler G, Amemiya C, Jansen G, Neville C, Narang M, Barceló J, O’Hoy $\mathrm{K}$, et al: Myotonic dystrophy mutation: an unstable CTG repeat in the $3^{\prime}$ untranslated region of the gene. Science 1992;255:1253-1255.

7 Harley HG, Walsh KV, Rundle S, Brook JD, Sarfarazi M, Koch MC, Floyd JL, Harper PS, Shaw DJ: Localisation of the myotonic dystrophy locus to $19 \mathrm{q} 13.2-19 \mathrm{q} 13.3$ and its relationship to twelve polymorphic loci on $19 \mathrm{q}$. Hum Genet 1991;87:73-80.

8 Louprasong AC, Light DJ, Diller RS: Spider dystrophy as an ocular manifestation of myotonic dystrophy. Optometry 2010;81:188-193.

9 Kimizuka Y, Kiyosawa M, Tamai M, Takase S: Retinal changes in myotonic dystrophy. Clinical and follow-up evaluation. Retina 1993;13:129-135.

10 Krishnan R, Lochhead J: Spontaneous bilateral lamellar macular holes and foveal schisis associated with myotonic dystrophy type 1. Clin Experiment Ophthalmol 2010;38:82-84.

11 Makino S, Ohkubo Y, Tampo H: Butterfly-shaped pattern dystrophy in myotonic dystrophy. Intern Med 2012;51:2253-2254.

12 Kim US, Kim JS, Hwang JM: A case of myotonic dystrophy with pigmentary retinal changes. Korean J Ophthalmol 2009;23:121-123.

13 Velazquez-Martin JP, Pavlin CJ, Simpson ER: Association between uveal melanoma and myotonic dystrophy: a series of 3 cases. JAMA Ophthalmol 2013;131:246-249. 
Case Reports in

Ophthalmology
Case Rep Ophthalmol 2013;4:129-133

DOI: $10.1159 / 000355385$

Esteves et al.: Pattern Dystrophy of the Macula in a Case of Steinert Disease
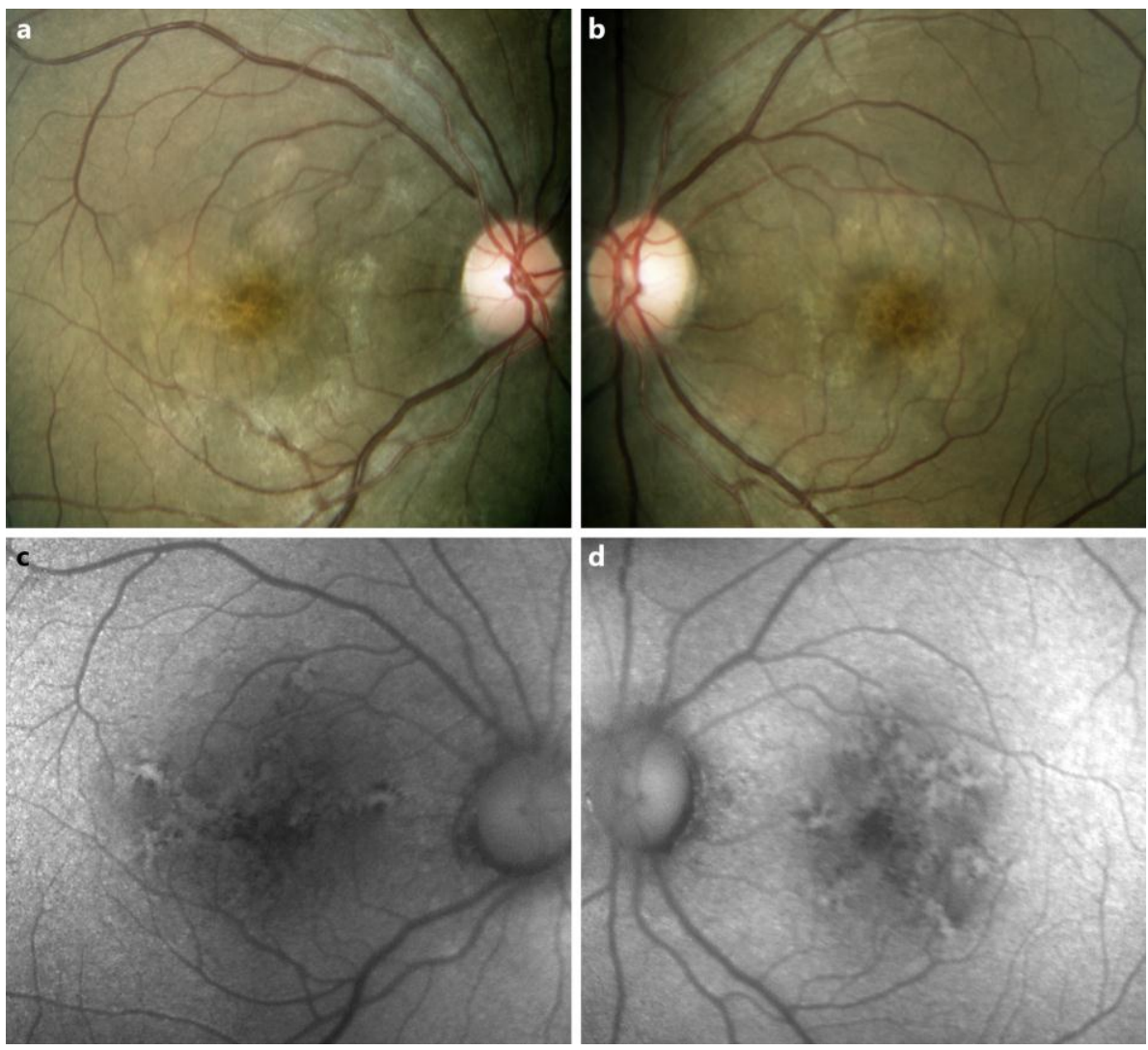

Fig. 1. Color photographs (a, b) show bilateral asymmetric irregular diffuse hypopigmented macular changes associated with focal hyperpigmented areas. A radial pattern of hyperautofluorescence was seen in the short-wavelength fundus autofluorescent images (c, d), consistent with butterfly-shaped macular pattern dystrophy. These lesions were associated with hypoautofluorescent patches corresponding to the areas of RPE hypertrophy. 
Esteves et al.: Pattern Dystrophy of the Macula in a Case of Steinert Disease
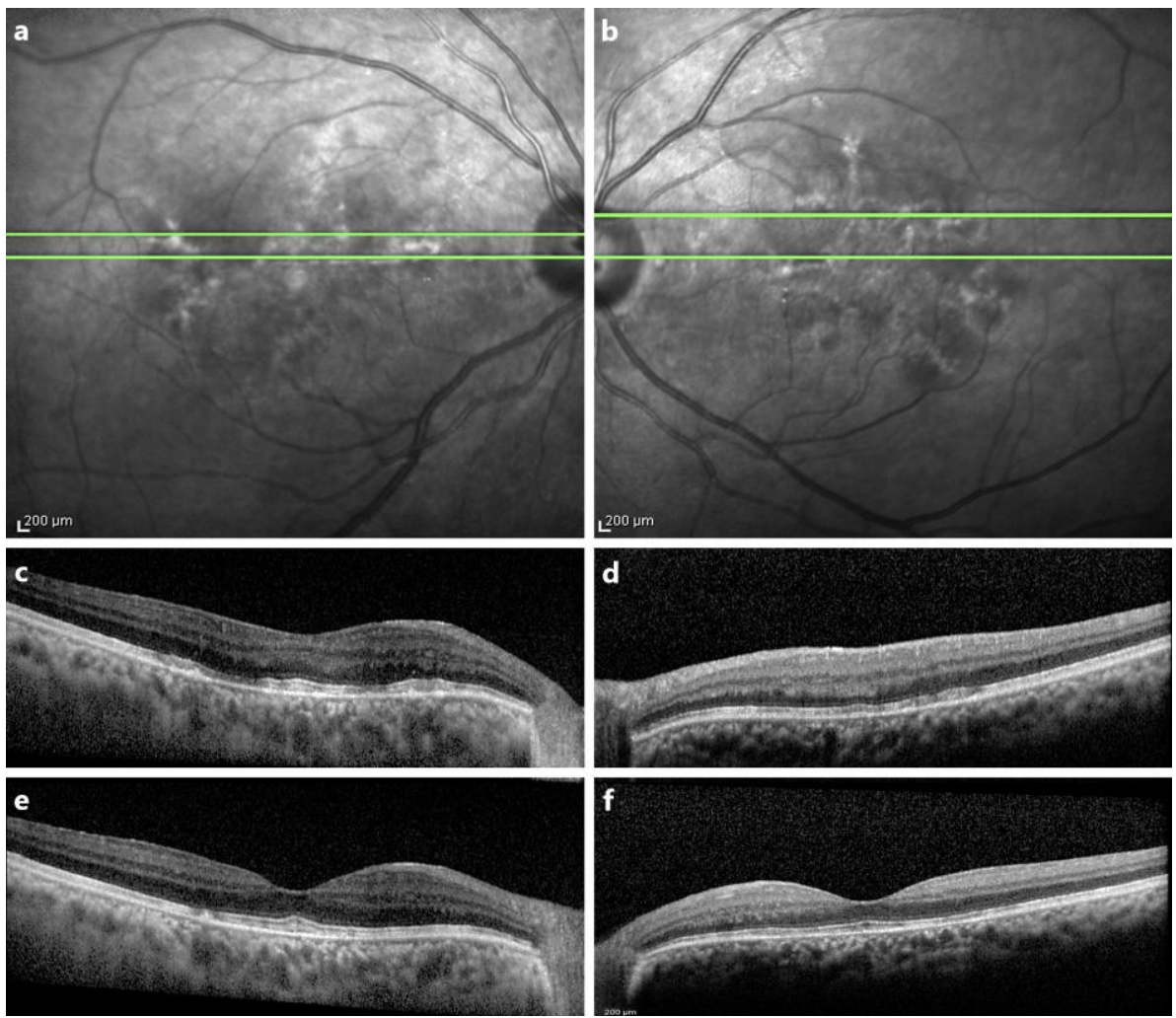

Fig. 2. The near-infrared fundus autofluorescence images (a, b) show a radial hyperautofluorescent pattern overlying a hypoautofluorescent background (butterfly-shaped macular pattern). Spectraldomain optical coherence tomography scans (c-f) reveal the presence of a diffuse subretinal hyperreflective material replacing the normal interdigitation zone with adjacent areas of mottled disruption of the outer retinal layers and focal hyperreflective subretinal deposits consistent with acquired vitelliform deposits. 